\title{
THE FRAMEWORK FOR INVESTIGATING DIRECT MANUFACTURING INVESTMENT OVERSEAS
}

\author{
F. Michael AdLER*
}

The purpose of this paper is to review critically, though far from exhaustively, some of the outstanding issues in the economic analysis of U.S. direct foreign investment activities. The unsurprising main conclusion is that the complexity of the issues and the multiplicity of contributing factors and inter-relationships will continue to preclude for some time to come resolution of the debate over whether direct investment abroad should be controlled. While the conclusion itself borders on the obvious, the route to it is less so.

The decision as to whether foreign investment activities should be controlled depends on two logical choices which correspond to two possible interpretations of the word framework appearing in the title. First, one must define the national policy problem which direct investment controls are supposed to solve. Already at this initial stage, the United States and others are confronted by dilemmas. For, to select the balance of payments crisis as the starting point, as the United States has, is to ignore other essential aspects of national well-being which also are affected by direct investment abroad. Further, even if the balance of payments context is chosen as most appropriate, the deficit can be reduced by alternative methods some of which require no direct investment control at all. The relevance of direct investment controls to policy is logically, therefore, quite narrowly confined to the choice of one very particular policy framework. These issues are discussed in Section I.

To make the decision to regulate direct investment abroad implies a fairly careful balancing of the costs and benefits of so doing. Measuring these costs and benefits then becomes a crucial issue. The deficiencies of most past and recent research in this regard are emphasized in Section II. A different choice, that of an improved framework or methodology within which the requisite information can be specified and analyzed, must therefore be made. Section II proceeds to argue for a promising econometric approach which, though it falls short of perfection, enjoys major advantages. Conclusions are briefly outlined at the close.

\section{The Policy Dilema}

Any government's preoccupation with direct foreign investment entering or leaving its borders stems from two sources. The first, arising from the nation's network of political and commercial relations with other countries, is the size of

- Assistant Professor of Business, Graduate School of Business, Columbia University. 
the total welfare gain from foreign investment and its distribution between the home and host markets. The second is the balance of payments. In the policy context, as well as analytically, the matter of the welfare effects is logically prior to that of the balance of payments. It is presumably upon the former that political priorities and target amounts of foreign investment should be set.

Needs arising from these two sources are not necessarily consistent. For example, a nation is better off the more it can consume. To reduce imports in pursuit of a balance of payments surplus will decrease the population's welfare position. In addition, many welfare components affected by direct investment activities such as the regional distribution of internal employment, competitive conditions, and problems associated with the managerial control of local companies have only a very indirect impact on the balance of payments. However, could the welfare effects be ascertained with certainty, balance of payments considerations could be removed to the background.

Unfortunately, it is exactly the welfare outcomes of foreign investment in the donor and recipient countries which are most elusive. Theory so far has been able to provide little assistance. Assuming perfect competition in all markets and no barriers to capital flows, most economic theory has suggested that foreign investment would proceed too far and reduce the welfare status of the investing country. ${ }^{1}$ Recently theorists have adopted a more agnostic stance. When assumptions are relaxed to include changes in the terms of trade, ${ }^{2}$ and especially transportation costs, tariffs, imperfectly competitive markets, and barriers to capital flows, ${ }^{3}$ foreign investment may fall short of its optimal level. Development economists have been cautious in their enthusiasm for foreign investors on behalf of developing countries whose governments' policies reveal little consistency. ${ }^{4}$ General or partial equilibrium theory, in fact, falls far short of providing a framework within which all the relevant measurements can even be identified, much less specified and carried out. No hope for improved information can be entertained for the near future.

Priorities and targets for foreign investment have therefore been and will continue to be hard to set. In the absence of guiding welfare principles there would probably be less need for elaborate national direct investment policies, in the United States or elsewhere, were it not for continuing international monetary crises. Without globally severe balance of payments pressures, ad hoc international-or at least bilateral-agreement could more easily be reached over such problems as the division

\footnotetext{
${ }^{1}$ Jasey, The Social Choice Between Home and Overseas Investment, 72 Econ. J. 105 (1960); Kemp, Foreign Investment and the National Advantage, 38 Econ. Record 56 (1962); MacDougall, The Benefits and Costs of Private Investment from Abroad, 22 BuLL. OF THE OXFord U. INsT. OF STATISTICs $187-212$ (x960).

${ }^{2}$ See Pearce \& Rowan, A Framework for Research Into the Real Effects of International Capital Movements, 12 Revista Internazionale di Scienze Econoniche e Commercinli 959 (1965).

${ }^{3}$ M. Kemp, The Pure Theory of Internationaz Trade $20 \mathrm{I}$ (1964).

'S. Enke, Economics for Development 277-98, 444-83 (1962); Singer, The Distribution of Gains Between Investing and Borrowing Countries, 40 Ax. Econ. Rev. 473 (1950).
} 
of control in international enterprises, antitrust provisions, and other political issues. It is the search for balance of payments equilibrium which, particularly in the United States, has raised direct investment and its restraint to eminence in the economic policy debate. Let us examine some aspects of the U.S. case. The main problem to be addressed is the question of the logical place of direct investment controls in over-all balance of payments policy. The over-all policy issue may be dealt with first.

One may still doubt whether the U.S. balance of payments is in fundamental disequilibrium. The United States has enormous commercial and industrial strength. Also, the reserve currency status of the dollar requires the United States to supplement world liquidity by running periodic deficits. Additionally, the value of marketable U.S.-owned foreign assets exceeds the value of U.S. assets held by foreigners. In particular, foreign investment probably serves to increase the U.S. longterm wealth position abroad if only because others have objected to financing ventures yielding between ten and twenty per cent with relatively cheap local funds. However, a crisis of confidence in the dollar continues to loom in the offing. The U.S. government feels compelled to find a solution. The implicit assumption, in other words, is that the U.S. deficits indeed reflect fundamental imbalance.

Three distinguishable, though related, courses of action present themselves. Each may be considered in isolation though in practice a combination would be likely. The first is a major domestic deflation. Such action has (and should have) been ruled out by successive administrations, including the present. The tail should not wag the dog. International transactions constitute a small percentage of U.S. GNP, and the deficit is their residual. The domestic hardships, in terms of unemployment, which would probably most severely affect the most explosive elements in the population, are too high a price to pay for balance of payments relief. However, some measure of disinflation is probably required.

A second global solution, favored by many academic economists, is by some combination of methods explicitly to devalue the dollar. A massive revaluation in the official price of gold could buy for the United States valuable time by increasing its reserves. Fluctuating exchange rates, in the form of a crawling peg, could be combined with measures to decrease inflation and continuing efforts to negotiate multilateral agreement over future rules of adjustment to international deficits and surpluses. Over a slightly longer haul such policies could diminish the deficit and, by affecting all payments uniformly, reduce the need for the government discriminatorily to intervene in particular classes of foreign transactions. For a variety of reasons, global solutions of this sort have not proved practicable. Governments are reluctant to surrender sovereignty in pursuit of international adjustment rules. In a world of pegged rates, even a crawling peg seems too radical. Nor is it clear that U.S. citizens and, in particular, direct foreign investors would have the courage to face up to and not to resist the uncertainties to which they would be exposed under 
such plans. However, in the context of a global approach, no specific direct investment control is required.

As an alternative to an explicit, global devaluation of the dollar, the question then is whether, following the Roosa plan of the early rg6os, effective devaluation can be achieved piecemeal through the selective control of each balance of payments account. The goal should be to penalize all outflows uniformly as they would be under outright devaluation, and, conversely, so to reward inflows. To be sure, such a method is cumbersome and complex. Reductions in different outflow categories will vary unpredictably in the degree to which they can save foreign exchange. Moreover, the government is required to discriminate among the classes of Americans upon which the most hardship is to be imposed: such choices too frequently give way to political and administrative convenience rather than considerations of the national interest.

Such disadvantages notwithstanding, variations on the Roosa plan are almost overwhelmingly attractive to government administrators in the United States and abroad. First, they fit into present, prevailing policies of selective intervention, viz., tariff policies and currency regulations elsewhere. Second, each act of regulation is limited and politically can be isolated for specific negotiation with foreign governments. Third, despite lip service to the elusive ideal of uniformity, legislators are often quite willing to pass discriminatory controls. To propose piecemeal regulation is easier and more assured of passage than radical reform. Groups selected for control may not be able to mount effectual opposition. Divided they may be ruled more effectively. The present balance of payments programs in the United States have developed in the Roosa tradition. Private foreign lending and investment were selected as the first (and easiest) targets for control.

In the framework of Roosa measures, each balance of payments outflow category is individually a candidate for regulation. There is no reason to allow, and every reason to prevent, the escape of any large body of transactions such as imports, tourism, or, for that matter, foreign lending by banks and direct foreign investment. Inter alia, direct investment control is a logical component of the policy mix. Resistance to-and demands for complete freedom from-such regulation must be couched either in terms of responsible global alternatives to the entire piecemeal approach or, less convincingly, on the grounds that any partial imposition of controls imposes unjust political inequities and damaging economic inefficiencies. Industry has not so far shown willingness to combat official policy initiatives by espousing global approaches to the balance of payments problem. Moreover, business arguments against discriminatory treatment have been considered by government officials to be largely self-serving and composed of assertions unsupported by proof. Consequently, industry's opposition to direct investment regulation has been ineffectual.

The problem is that the corporate challenge to government policy procedures contains warnings of real dangers which so far have gone unheeded. The issue is 
not merely that present policies discriminate inconsistently. In the context of a complete Roosa program applied sequentially one could probably justify the selection of private investors for regulation first. It might be argued that the restriction of one kind of outflow yields at least some balance of payments savings and in a time of crisis, is therefore better than nothing. The argument may be completely wrong, however. Unless all outflows are penalized uniformly the balance of payments could be worse off in the short run with what amounts to a partial devaluation or a multiple exchange rate, as the experience of some underdeveloped countries suggests. To tax one form of outflow is implicitly to subsidize others to which, therefore, citizens may shift. If the substitution is from a form of foreign outlay which yields earnings in foreign currency to one which does not, the balance of payments will suffer. It is consequently entirely possible that the temporary relief, which foreign investment restraint has seemed to yield, is completely illusory and is the coincidental by-product of time lags in the shift.

At best each reduction in foreign investment outflows will yield a one-shot saving of foreign exchange which will reduce the deficit if the savings are not squandered elsewhere. Continuing appreciable balance of payments relief may, however, require successive and increasingly severe controls unless the burden of the policy is shared by accounts other than direct investment. The transformation of control from voluntary to mandatory may be evidence of such a progression. Little harm seems so far to have been done to longer-term U.S. interests. But questions arise as to how long the danger of longer-term damage can be averted. For in the present, narrow balance of payments context of foreign investment policy, the aforementioned absence of unambiguous welfare guidelines has permitted-and perhaps forced-policy makers to emphasize short-range at the expense of long-range objectives. However, it is next to impossible to discover whether and to what extent the next increment of curtailment will have harmful long-run effects which clearly outweigh any possible short-term benefit. $^{5}$

To summarize, direct investment control in the United States has become a matter of concern for national economic policy, not as a result of balancing welfare benefits and costs as it should have, but as the consequence of a narrower focus on the choice of particular means to reduce the deficit. Once domestic deflation has been ruled out as the main instrument, an effective change in the exchange rate is required. Devaluation can be achieved through global measures or, alternatively, by selective manipulation of each balance of payments account. All choices at this stage are distasteful. Global solutions are probably superior for they require less direct government intervention and control. Market mechanisms are allowed to govern the manner in which all accounts are affected on the way to equilibrium. Officials are not required to make the unwarranted national welfare judgments implicit in any

${ }^{5}$ Adler, The High Cost of Foreign Investment Restraint, 3 Colum. J. WorLd Bus. 73 (1968). 
attempt to regulate individual accounts. For to do so consistently presupposes knowledge of the value to the nation of each form of foreign expenditure as well as accurate estimates of the balance of payments impact of curtailing it.

Direct investment control becomes a logical component of balance of payment policy only in the context of the piecemeal Roosa approach. To undertake such a program may be not only inequitable but also inefficient. In a world of pegged exchange rates and planned economies there may, however, be no alternative. Generally, uniformity of control across all balance of payments accounts should be stressed as a condition for achieving real balance of payments improvement, which may be impossible with only partial regulation.

Even if direct investment regulation is accepted in this framework, the form of intervention is not a moot matter. Direct administrative control of individual investment abroad should be resisted at all costs. The absence of barometers of economic efficiency can foster favoritism and the waste of top-level manpower. Nor should the dollar amount of a firm's permitted foreign investment be tied to past overseas earnings. The established firm is favored over the newcomer from whom the nation might, in fact, derive the greater future benefit. A method more in keeping with the uniformity goal would be to tax all investment outflows and to provide a tax credit on repatriated funds. The tax approach can fairly simply be extended to other accounts as well.

On practical grounds, some variant of the Roosa plan is most likely to provide the underpinnings for national balance of payments policy in the foreseeable future. Direct investment control will continue to pose a problem which will have to be considerably better understood than it is at present. Questions connected with specifying realistically the determinants of the international payments consequences of direct foreign investment and the ways they should be investigated are the subject of the next section.

\section{II}

\section{RESEARCH Issues}

The discussion of the policy dilemma and related matters will provide one part of the framework within which research issues associated with corporate foreign investment activities can be specified. The scope of the inquiry should at this point be expanded. Interest in a better understanding of direct investment abroad arises not only from considerations of national policy but also from the managerial problems of the investing enterprises which hitherto have been omitted. Both foci will be touched upon in what follows.

\section{A. Past Research}

Corporate managerial questions have normally given rise to normative research whose objective is the improvement of foreign direct investment decision procedures. 
However, no attempt will be made here to review the normative international business literature independently of its implications for positive research. The reasons are several. Normative problem solving for international business has so far failed to propose other than fragmented partial solutions to isolated problems: lacking is the organizing and unifying concept of an over-all corporate objective. Often, less sophisticated thinking than has already been devoted to purely domestic issues is applied to the more complex, multi-market problem. The disorganized state of the normative art has prevented it from providing unambiguous criteria for optimal selections among mixes of domestic and foreign investment opportunities. The absence in the normative literature of a consistent set of principles for international business decisions renders most of the work useless for present purposes.

Equally, however, most past analysis of data aggregates has proved singularly unproductive of balance of payments policy guidelines for the nation or for business. Until very recently, the precepts of neoclassical theory and official preoccupation with short-term balance of payments control have jointly conspired to confine investigation to the capital flow characteristics of direct foreign investment. The analytical paradigm was usually the set of international monetary and economic relations in an implicit general equilibrium context. Within such a context successive studies have attempted to identify in isolation the impact of changes in direct investment funds flows on various individual external accounts. ${ }^{6}$

In part it is the analytical framework which is too restrictive. Direct investment funds are assumed to flow solely in response to (covered) yield differentials. All flows are induced: ignored is the autonomous nature of many, if not most, investment decisions. Absent, too, is any consideration of the multitude of factors, other than yields which are known with certainty, which normative analysts have found to motivate direct investment decisions. ${ }^{7}$ In addition, general equilibrium analysis is by its nature static: transitions from one stock level to another are instantaneous and friction free.

The thought forms and assumptions of traditional international macroeconomics are only imperfectly adaptable to the microeconomics of direct investment. Current balance of payments theory has been developed largely in terms of interindustry relations among national economies. Predictions of the effects of interactions among relevant factors have been deduced from two factors, two goods, two country models

\footnotetext{
${ }^{\circ}$ Staff of the Subcomem. on International Exchange and Pamients of the Joint Economic Comm., 87th Cong., 20 Sess., Factors Affecting the United States Balance of Paxments 395, 458-69 (Comm. Print 1962); Address by Gerlof A. Homan, Annual Meeting, Western Economic Ass'n, August 1962; E. Phillips, The Long-Run Implications of Direct Foreign Investment for the United States Balance of Payments, I964 (unpublished thesis in University of Illinois Library).

${ }^{7}$ See Y. Afaroni, The Foreign Investment Decision Process (rg66); R. Bast, Determinants of U.S. Private Direct Investment in Foreign Countries (I963); J. Polk, I. Meister \& L. Veit, U.S. Production abroad and the Balance of Payments (ig66); H. Robinson, The Motivations and Flow of Private foreign Investuent (ig6r).
} 
with constant returns to scale, no uncertainty, and other perfect market assumptions. The list of deficiencies could go on endlessly. The point is that manufacturing direct foreign investment is an intraindustry process involving goods with nonzero elasticities of substitution in consumption. Investment occurs under conditions of technological change, varying scale economies, uncertainty, nonzero transportation costs, discriminatory tariffs, oligopolistic competition, and bounded rationality. What is more, conceptual difficulties are compounded by severe data problems.

It is therefore not surprising that the results of research to date are more helpful to academicians than to practitioners. For example, even the most complete of the available empirical studies are so designed as to lead to the calculation of balance of payments recoupment periods. The number of years to the recoupment or payback of a given investment outlay is obtained by dividing the initial balance of payments outflow by a denominator containing all the annual inflows, including all funds remissions and related trade effects, attributable to the foreign expenditure. ${ }^{8}$ Analytically, the balance of payments payback period is a useful device for bringing together under one umbrella all the diverse factors affecting and affected by direct investment spending and growth abroad. This is the main justification for its popularity.

However, the computed numerical values of the recoupment periods can make only a limited contribution to the problem of formulating balance of payments policy even in the context of the Roosa program. The issue is quite apart from data problems and the expectational validity of average estimates based on time series of past outcomes. In the first place recoupment periods obviously ignore the home and host country welfare considerations upon which, as has already been said, consistent policy priorities and comparisons can best be based. In the second, not all categories of external payments give rise to directly associated, identifiable two-way flows. No recoupment period can be computed for tourism, for example, which therefore cannot be compared on a recoupment basis with direct investment. Thirdly, balance of payment payback periods do not measure the total (value of the) balance of payment flows over the life an an investment. Finally, the assumption embedded in the recoupment rates of a fixed linear functional relationship between outflows and inflows is probably a vast oversimplification. It is not therefore obvious for how long the payback period can be used to measure the marginal effect on inflows of changes in outflows.

Quite clearly, recoupment computations provide little assistance in achieving the uniformity objective which should underlie any imposition of the Roosa program. All the direct investment payback periods can do is measure approximately the probability that a forced cutback in investment outflows will bring about, for a time, a reduction in the gold drain: the longer the recoupment period, the greater the

\footnotetext{
${ }^{8}$ See Address by Gerlof A. Homan, supra note 6; Staff of Subcomm. on International Exchanon and Payments of the Jonnt Economic Coms., supra note 6.
} 
chance, provided of course that U.S. citizens do not compensate by switching their foreign expenditures to other accounts. The usefulness of such information is confined to times of emergency and crisis.

What is more, short recoupment periods may not universally be good and long periods bad for the United States. Present U. S. policies for aiding underdeveloped nations would be subverted were payback periods too short. In fact, were foreign governments to believe that balance of payments recoupment of U.S. direct investment flows took only two years or less, they might move themselves to restrict U.S. ownership within their borders. Their actions might be more severe than the present U.S. mandatory control program. The problem of choosing a "best" payback period for policy purposes is recognized in Washington. It has not been solved.

To summarize, the value of research to date can be questioned on several grounds. For policy purposes, its assumptions appear oversimplified. There is no certainty that all the appropriate factors have been taken into account. The conceptual shortcomings combined with the difficulty of obtaining adequate expectational data may have given rise to estimates of future balance of payments effects of foreign investment which are no longer accurate: the point is that one cannot tell. In any case, the present focus on payback criteria, however convenient analytically, has only limited applicability to the issues involved in using the Roosa program for balance of payments adjustment. Certainly, research designed to argue for payback periods of a particular length or which accepts the established framework but tries to achieve realism by relaxing assumptions inconsistently is completely valueless. ${ }^{9}$ Finally, none of the thought forms so far applied to direct foreign investment measurements have been viewed by businessmen as being clearly related to their own decision processes. However, the business community has signally and conspicuously failed to supply data or models for alternative estimates to be made.

\section{B. A Research Proposal}

A major missing element is a positive econometric theory of the internationally diversified manufacturing firm. Such a theory, incorporating specification of all the relevant variables and interactive relationships, can provide a viable model of the motivation and determinants of the corporate decision to invest abroad. For unless the real and financial determinants of individual firms' investment flows can be described and understood, analysis of the factors and conditions which cause movements in aggregate direct investment expenditures and receipts, required for implementing the Roosa program, may be blocked. To be sure, full scale use of such an approach is, as a practical matter, some distance off if only because of difficulties in getting data. However, a reasonably complete description of the methodology can even at this stage provide useful insights. To these let us now

\footnotetext{
${ }^{\circ}$ See J. Behraran, Direct Manufacturing Investment, Exports and the U.S. Balance of Payments Position (I968).
} 
turn. First to be considered are the relevant variables which must be taken into account. Later the strengths and failures of the suggested model for corporate and national policy making can be discussed.

To start with, a quantifiable description of direct investment requires an aggregable micro-theory of the investing firm. Departing from the classical goal of profit maximization, the theory should posit a multiple-plant, multi-market, multi-product, monopolistic competitor whose objective is the maximization of the market value of its shares. At least six classes of relevant variables and relationships would have to be brought into play:

(I) Accelerator variables, including the effects of changes in output relative to capacity on capital budgets, and the commitment of funds to subsidiaries. Contrary to some current theorizing, one would expect a U.S. firm's investment abroad to respond (with lags) to changes in expectations regarding conditions in each foreign market.

(2) Production functions for all present and planned products which ultimately determine cost-volume relationships and the cost sensitivity of substituting fixed for variable factors (and vice versa). For example, one could posit for each product or plant everywhere constant (or variable) elasticity of substitution production functions with varying economies of scale possibilities in different locations. Issues associated with joint product costs would have to be considered. Together these factors determine production costs.

(3) Income and price demand relationships so defined as to take account of the imperfectly competitive conditions generally to be found in the United States and elsewhere. For price elasticities will not, as is too often assumed, be infinite. Nor will price cross elasticities of demand for the firm's different products necessarily be zero. And if components of the product line appeal to different consumer groups, the income demand elasticities will differ. Such factors affect the firm's revenue possibilities in each location.

(4) Distribution costs, including transportation costs and tariffs as well as storage charges. Apart from their effect on profits these factors are key determinants of the firm's optimal locations.

(5) Demand and supply of funds variables. The question is the cost of money capital in each location. The firm's demand for money capital can be defined in terms of its resource requirements. Cost functions describing the supply conditions for debt and equity in each capital market can be assumed, and constraints on the free international movement of money capital can be considered. In general investment decisions should be sensitive to the cost of money.

(6) Risk variables including business, financial, political, and exchange risks in each location. These risks affect the expected values and variability of the returns to be obtained by the parent company and its stockholders from foreign opera- 
tions, and therefore the market cost of each kind of funds and the value of the firm's shares which is to be maximized.

A comparative static econometric model incorporating these six classes of factors could produce for a single firm information regarding potentially desirable international directions of flow of both funds and goods. Classical economic theorists have long understood that the mere existence of transportation costs among markets and, a fortiori, the presence of scale economies can make production in more than one location worthwhile. Such insights are included here. Moreover, the model incorporates the National Industrial Conference Board's organic thesis. ${ }^{10}$ For, in addition, there are mechanisms which determine (induced) demand for real assets and inputs, and the resulting demand for money everywhere, as well as functions which can specify where that money will be raised and sent. The multilateral flows of money capital no longer respond simply to covered yield differences, however. They are determined complexly by the simultaneous resolution of all the forces which determine the optimal planning solution for the company's worldwide structure, i.e., investment, production, and finance. The model can be used positively, as a theory of the determinants of corporate investment abroad, or normatively, as a planning framework within which improved decisions can be specified.

To propose a research program based on such considerations may sound overly ambitious. However, several econometric studies, utilizing essentially variations of variable classes (I) through (5), have either been completed or are planned.11 Naturally the value of their predictions will depend on the realism of their assumptions. Adequate data are impossibly hard to obtain. Little expectational information is available as to investment plans or production functions. Empirical estimates of demand and supply functions for goods and funds for all practical purposes do not exist: they remain hidden in the minds of the decision makers. Consequently econometricians are forced to assume constant lag accelerators, linear or L-shaped production functions with constant returns to scale, and perfect competition in factor, product, and money capital markets. At best, in the last instance, demand and supply curves are assumed linear. Under such restrictive assumptions, optimal production, investment and financial decisions are hard to specify, and not much can be said about intrasystem flows between periods. Nevertheless the conclusion of one investigator that a profit maximization model incorporating some of the above factors provides the best explanation for newly collected data is startling confirmation of the validity of the over-all approach. ${ }^{12}$

\footnotetext{
${ }^{10}$ See PotK, MeIster, \& VEIT, supra note 7.

${ }^{11} \mathrm{~J}$. Popkin, Interfirm Differences in Direct Investment Behavior of U.S. Manufacturers, 1965 (unpublished thesis in University of Pennsylvania Library); A. Severn, untitled, unpublished work in progress (U.S. Dep't of Commerce); G. Stevens, Fixed Investment Expenditures of Foreign Manufacturing Affiliates of U.S. Firms: Theoretical Models and Empirical Evidence, 1967 (unpublished thesis in Yale University Library).

${ }^{12}$ G. Stevens, supra note II.
} 
The normative aspects of the proposed research should be emphasized. For individual firms (or industries) the construction of such models constitutes a reasonable format for internal corporate policy making and planning, as outlined by Vickers. ${ }^{13}$ As corporate planning techniques become more sophisticated, the usefulness and relevance of the information to be obtained from analysis similar to that outlined above will become more apparent. Policy making for the nation as a whole may also be viewed as an exercise in planning. In the direct foreign investment context the national and corporate planning problems share methodological elements. In other words, the kinds of information which seem to be required-and hopefully will eventually be provided-for corporate planning constitutes, when aggregated across large groups of firms, a major portion of the data inputs for planning national balance of payments policy. In each case normative problem-oriented research and recommendations can be placed in the relevant positive framework.

For national purposes, however, additional information is also needed. What is required is a description of the interindustry connection between foreign investment, production abroad, and international trade over and above the data on intrafirm or intraindustry relationships. Finally these factors must be related to national policies with respect to domestic income distribution and growth and to the entire network of the nation's interactions with other countries. Clearly, in this broader forum, the econometric approach offers no easy solution for policy planners. If and when the corporate sector begins to produce the relevant information, a potentially severe aggregation problem will have to be solved. It is unlikely that the net effect of foreign investment for the nation as a whole will be the simple sum of each firm's outcomes. In fact, any theory of the determinants of aggregate U.S. direct investment decisions abroad would logically have to be nested in parent-models of the processes of capital, income, and price formation in the United States and other countries.

The enlarged analytical compass is required to determine the aggregate net impact of U.S. direct investment abroad on such critical dimensions as terms of trade changes, income changes in the home and host countries, and the relationship between local production by U.S. subsidiaries and local firms, and imports, i.e., import substitution abroad. However, while a beginning has been made, ${ }^{14}$ international economic theory as yet does not provide all-inclusive, parametric models within which all the relevant phenomena can be specified and measured. In addition, the alternative position-what could be expected ex ante to happen in the absence of U.S. direct investment-will always remain a matter of conjecture and hypothesis. Nor finally does the method at hand completely solve the problem of devising policy criteria for direct investment which permit comparisons with other balance of payments accounts. Social utility factors, although easy to assume, are hard to specify

\footnotetext{
${ }^{18}$ D. Vickers, The Theort of the Firm: Production, Capital and Finance (ig68).

14 See Pearce \& Rowan, supra note 2.
} 
empirically. The difficulties of the present approach are manifest. On the other hand, one should not look for conceptual integration at the international level when it has proved elusive at the level of purely domestically oriented research.

Hurriedly, it should be added that even if all the theoretical and empirical obstacles could be overcome, econometric model building would be no panacea. First, and most importantly, the envisioned input data will be based in many cases on subjective estimates and guesswork. The results, therefore, will be subject to considerable uncertainty. In particular, the shifts in comparative advantage relationships which follow technological change and which probably underlie not only changes in trade patterns but new foreign investments as well ${ }^{15}$ will remain hard to predict. Second, econometric theorizing can easily remain barren of many institutional considerations with which normative researchers have legitimately been concerned. For example, the organizational, psychological, and sociological factors which affect the foreign investment decision are largely omitted except insofar as they are captured in the analysis of lags, at various points, and in the specification of certainty equivalents or risk-adjusted yields. Environmental matters, such as questions of corporate control, tax loopholes, and antitrust exposure which are of interest to lawyers and politicians, are included only very indirectly as part of the analysis of risk. However complex, econometric measurements are unlikely to exhaust all the relevant problems.

In the face of so many deficiencies, the usefulness of discussing, much less trying to apply, appropriate econometric techniques for analyzing U.S. manufacturing investment abroad might well be challenged. A defense on both counts can go beyond the statement that the frustrations of the planner may only rise to equal, but cannot exceed, those of the decision maker. For indeed the analysis cannot be less complex than the decision problem itself. Several specific ends are served by the preceding research proposal.

One contribution of the previous discussion is that it highlights our ignorance of the cause-effect relationships which underlie the decision to erect manufacturing subsidiaries abroad. On the one hand, national direct investment policy decisions have taken place in a factual vacuum. On the other, it would seem that corporate planning has not been able to integrate international activities in such a fashion as to provide consistent criteria for optimal company performance. Past research has not been of much help for the very reason that, in the absence of a theory of investment determination, the benefits and costs of investment and its curtailment could not be measured accurately.

Before present decision procedures can be improved, one must have specific knowledge of the causal variables and the manner in which they interact to produce final outcomes. A detailed taxonomy of factors such as that provided above can be

${ }^{15}$ Adler, supra note 5; Vernon, International Investment and International Trade in the Product Cycle, 80 Q.J. EcoN. 190 (1966). 
helpful. The specification of an econometric model, in addition to providing an explicit description of the foreign investment process which can be corrected should it prove wrong, also focuses attention on the phenomena which have been excluded. One can, in other words, be clear as to what exactly has been taken into account.

Even partial progress with the new approach can add considerably to the small store of hard information now on hand. Many factors, such as the relative desirability of increments of investment as opposed to tourism or aid, may continue to have to be excluded. However, the place, if not the exact manner, in which they might be incorporated can be made explicit. At least the more complex models at hand will deliver policy from its present misconception of linear tradeoffs between investment-related outflows and inflows. In other words, initial results could have the power to reveal more clearly than is now possible the payments consequences of direct investment control. Equally, as a result of better planning techniques corporations could determine more accurately the market value to their shareholders of extended commitments abroad. Were it worthwhile to reduce foreign investment, less control would be required.

Such findings might themselves justify the large investment which will be required to begin extensive econometric work at the corporate and national levels. But the greatest benefit of all may stem from the conjunction of the two. Well specified econometric simulations will certainly assist corporate planners. The data and results they produce can provide inputs for national policy planning. Business and government can then achieve agreement, which they have not so far, over the data requirements of direct investment policy. Further, communication can be enhanced by the common methodological aspects of the planning and policy formation processes in each sector. Such unity of thought, even if not of purpose, may sound Utopian. Yet it is a worthwhile objective for it represents the possibility of a vast improvement in industry's presently hostile and apprehensive attitudes toward official policy initiatives.

\section{Conclusions}

The main thesis of the paper can now be stated simply. Apart from the independent value of improved planning methods to the corporate sector, the need for the research program outlined in the previous section depends on the choice of the over-all policy framework. Academicians will continue to espouse global solutions to the U.S. balance of payments crisis and to be opposed by politicians and administrators, not to mention businessmen. One advantage of global solutions is that they obviate the need for selective, including direct investment, regulation. If, however, piecemeal Roosa measures are chosen to substitute for other, possibly superior, means of improving the deficit, direct investment control becomes logical and necessary. At that point, also, detailed and accurate information on the behavior of the direct 
foreign investment accounts and their responses to changing conditions at home and abroad is urgently required. And it is at that point that all the difficulties described above must be confronted. Perhaps the ongoing debate over direct investment regulation should be returned to the key underlying and unresolved issue. Why should the Roosa program continue to be viewed as the most appropriate route to balance of payments equilibrium? 